\title{
When Do Firing Costs Matter?
}

\author{
Giulio Fella* \\ Department of Economics, London School of Economics, London, UK \\ Department of Economics, Queen Mary and Westfield College, London, UK
}

February 1999

\begin{abstract}
This paper uses a strategic bargaining framework to reassess the effect of dismissal costs in models of voluntary separation. It shows that firing, as opposed to inducing a quit, is always an off-equilibrium strategy for firms in this class of models. Thus, dismissal costs can affect payoffs only if some exogenous event may force the firm to fire the worker despite it being suboptimal, or if the firm's assets are only partly specific to the relationship. In this latter case, dismissal costs increase the specificity of the firm's capital and depress ex post expected profits. In any case, firing restrictions do not affect separation decisions, as firms always find it profitable to induce workers to quit whenever separation is efficient. Involuntary separation is an essential feature of a world in which firing costs result in a lower probability of separation. In such a world, they may be welfare improving, as the separation rate is inefficiently high in the absence of firing restrictions.
\end{abstract}

JEL Classification: J32, J63, J65.

Keywords: Coase theorem, firing costs, involuntary separation.

\footnotetext{
*E-mail: G.Fella@qmw.ac.uk. Correspondence to: Department of Economics, Queen Mary and Westfield College, Mile End Road, London E1 4NS, UK. I am grateful to Charlie Bean and Paola Manzini for helpful comments. All remaining errors are my own.
} 


\section{Introduction}

The aim of this paper is to reassess the effect of firing costs in models of symmetric information and voluntary separation.

Firing costs, it is maintained, have two effects. First, they result in higher wages for incumbent workers and reduce firms' ex post profits. Yet, the literature in question assumes that dismissal costs result in higher insider wages, but does not explicitly model the mechanism behind this result. Firing costs are effectively treated as a tax on separation, whoever initiates it. This is clearly not the case in reality. Voluntary quits involve no statutory cost for firms. Second, it is contended that dismissal regulations result in higher relation-specific quasi-rents and an inefficiently lower separation rate, if only a part of the firing cost born by the firm accrues to workers ${ }^{1}$. On the other hand, a pure severance payment should not affect job duration.

The intuition behind this second claim is the following. If part of the firing cost is a tax (a third party payment), it has real effects if both demand and supply for labour are elastic. In fact, even red tape firing costs are not a tax, but rather a redistribution of property rights on the job. Ex post, nobody has an interest that the cost is actually paid. Since all the above mentioned models assume transferable utility and complete and symmetric information, Coase theorem would predict efficient separation independently from the distribution of property rights. Something is clearly missing from this literature and, given the widespread acceptance of this paradigm and the range of implications which have been derived from it, it seems important to look inside the black box to understand the mechanism through which dismissal costs affect actions and payoffs.

It is easy to understand why the existing literature has treated firing costs as a tax on any separation. If separation is voluntary, it is impossible ex post to distinguish between dismissals and quits. Modelling bargaining explicitly, as it is done in this paper, allows to meaningfully distinguish which party gains (ex ante) by the end of the match.

The framework we use encompasses all existing models of voluntary separation under risk-neutrality and symmetric information ${ }^{2}$.

\footnotetext{
${ }^{1}$ These two predictions are common to all equilibrium models of voluntary separation and symmetric information. See Lazear (1990), Burda (1992), Hopenhayn and Rogerson (1993) and Millard and Mortensen (1997).

${ }^{2}$ The competitive outcome obtains as a limit case when workers' bargaining power converges to zero.
} 
We model the bargaining process along the lines of the strategic bargaining literature pioneered by Rubinstein (1982) and use the random proposer model of Binmore (1987) to avoid asymmetries in the order of offers.

Firing costs alter the firm's outside option, but not the worker's. Workers do not get them if they stop bargaining and quit to trade with a third party.

We show that firing is never an equilibrium strategy. So, for firing costs to have an effect on the equilibrium outcome it has to be the case that either some exogenous event may force the firm to fire workers despite it being suboptimal, or that separation allows the firm to free assets which have a positive market value. Intuitively, firing costs increase the specificity of the firm's capital. If its assets are already fully specific - i.e. if its outside option gross of the firing cost is zero - under no circumstance will the firm find it profitable to pay the firing cost in order to trade with a third party. So the latter cannot affect equilibrium payoffs unless involuntary firing can take place with strictly positive probability.

Finally, the main result of the paper. Firing costs do not generate any additional joint quasi-rent and, hence, have no effect on the separation rate in models in which severance is voluntary in the absence of firing restrictions. Even when they do generate rents for workers, these rents and, hence, workers' mobility cost are always lower than the statutory firing cost. So, a firm will never dismiss a worker. When its surplus from the match is nonpositive, it will rather induce a quit by paying the worker a voluntary severance payment equal to her foregone rent. Under symmetric information legislated firing costs, whether received by workers or not, cannot affect the separation decision which is always socially efficient.

Dismissal regulations, may result in labour hoarding only when separation would otherwise be inefficient, that is when some form of exogenous or endogenous real wage rigidity prevents the parties from agreeing on a side-payment which makes separation jointly efficient. Since utility is non-transferable, efficiency depends on the initial distribution of property rights on the job. In the absence of dismissal costs, severance takes place whenever the firm's payoff is non-positive whether or not the joint return within the match is strictly lower than the joint return from separation. Dismissal costs reduce the firm's return from separation, by setting a minimum price for the exercise of the right to fire. So, provided they are high enough to ensure that the minimum trade price of the property right equals the value of employment continuation to workers, they induce the firm to terminate the rela- 
tionship efficiently, when the joint rent from the match is zero. We show that in a simplified version of the exogenous mobility cost model of Bertola and Ichino (1995a) a pure severance payment unambiguously increases aggregate welfare if wage rigidity results in involuntarily costly workers' mobility.

The existing empirical evidence provides support to the relevance of the mechanism we highlight in this paper. Both the positive correlation between measures of job security and tenure and the impact on net employment creations of reforms increasing labour market flexibility are consistent with the involuntariness of separation and difficult to reconcile with the predictions of models of efficient separation

The paper is structured as follows. Section 2 describes the economic environment. Sections 3.1 shows the irrelevance of dismissal costs when firms' investment is fully irreversible. Section 3.2 analyses the effect of dismissal costs on payoffs when either the firm's assets have a positive resale value or involuntary firing is possible. Section 4 demonstrates that dismissal costs cannot affect separation rates and tenure in models of voluntary unemployment, but may induce efficient separation when real wage rigidity results in involuntary separation. Section 5 briefly discusses the empirical evidence on the relevance of involuntary separation. Section 6 concludes.

\section{Economic environment}

We consider a firm and a worker bargaining over the wage at which to exchange one unit of labour. This is sensible if the net return to labour is higher within the relationship due to specific investment or (non-statutory) turnover costs. As in most of the literature on search unemployment, bargaining is assumed to take place over a stock (i.e. the present value of expected surplus) rather than a flow ${ }^{3}$. The value of labour to the firm is a random variable $y$ with nonnegative support and, without loss of generality, the utility of leisure is normalized to zero. So the net surplus from trade is $y$ and the worker's utility, if trade takes place, coincides with the wage. Information is assumed to be symmetric. Both parties can decide to break the relationship irrevocably and trade outside. The return to doing so is $w^{o}$ for the

\footnotetext{
${ }^{3}$ In reality, trade over labour services concerns a flow rather than a stock. In the absence of contracts this makes no difference, as the parties do not trade during bargaining. The effect of contracts is discussed in section 3.1.
} 
worker and $\pi^{o}$ for the firm ${ }^{4}$. Also $w^{o}$ is assumed to be a random variable with nonnegative support.

Since the scope for efficient risk-sharing is well understood ${ }^{5}$, we assume both parties are risk-neutral.

Bargaining takes place over an infinite ${ }^{6}$ time interval $[0, \infty)$ divided into discrete periods of length $\Delta$. Each bargaining round is indexed by $n$. As in Binmore (1987) and MacLeod and Malcomson (1995), we assume that at the beginning of each bargaining round $n$, nature, $\mathfrak{N}$, chooses which player is entitled to make an offer, the worker being chosen with probability $\gamma \cdot \gamma$ is then a measure of the worker's bargaining power; the higher is $\gamma$, the higher is the cost to the firm of rejecting an offer, since there is a high probability that it will find itself in the same position in the next bargaining round.

The parties discount the future at the common instantaneous rate $r$. So $\delta^{\Delta}=e^{-r \Delta}$ is the discount factor for one bargaining round.

If the firm fires the worker and trades with a third party, it is bound to pay a firing $\operatorname{cost} F$ of which $Q \leq F$ accrues to the worker. The possibility that the cost to the firm exceeds the payment to the worker is meant to capture any deadweight loss, such as redtape administrative costs, associated with firing. Contrary to all the existing literature, we realistically assume that quits involve no statutory cost to the firm and no payment to the worker.

The negotiation process has the following structure and is represented by the game tree in figure 1. In each bargaining round the agent entitled to make an offer proposes a wage $w_{n}$. The counterpart decides whether to accept $(\mathrm{A})$, take its outside option $(\mathrm{O})$ or reject $(\mathrm{R})$.

1. If $w_{n}$ is accepted, trade takes place and the game ends. The worker earns the wage $w_{n}$ and the firm makes a profit $y-w_{n}$.

2. If the party faced with an offer unilaterally abandons the negotiations and enjoys its outside option by trading with a third party, the game ends. If the worker quits to

\footnotetext{
${ }^{4}$ The outside payoffs are to be intended net of any non-statutory exogenous turnover cost born by either party.

${ }^{5}$ See, for example, Bertola (1996) and the original implicit contract literature pioneered by Baily (1974) and Azariadis (1975) and surveyed in Hart (1983) and Stiglitz (1986).

${ }^{6}$ Most of the results carry over to the case of finite time horizon.
} 


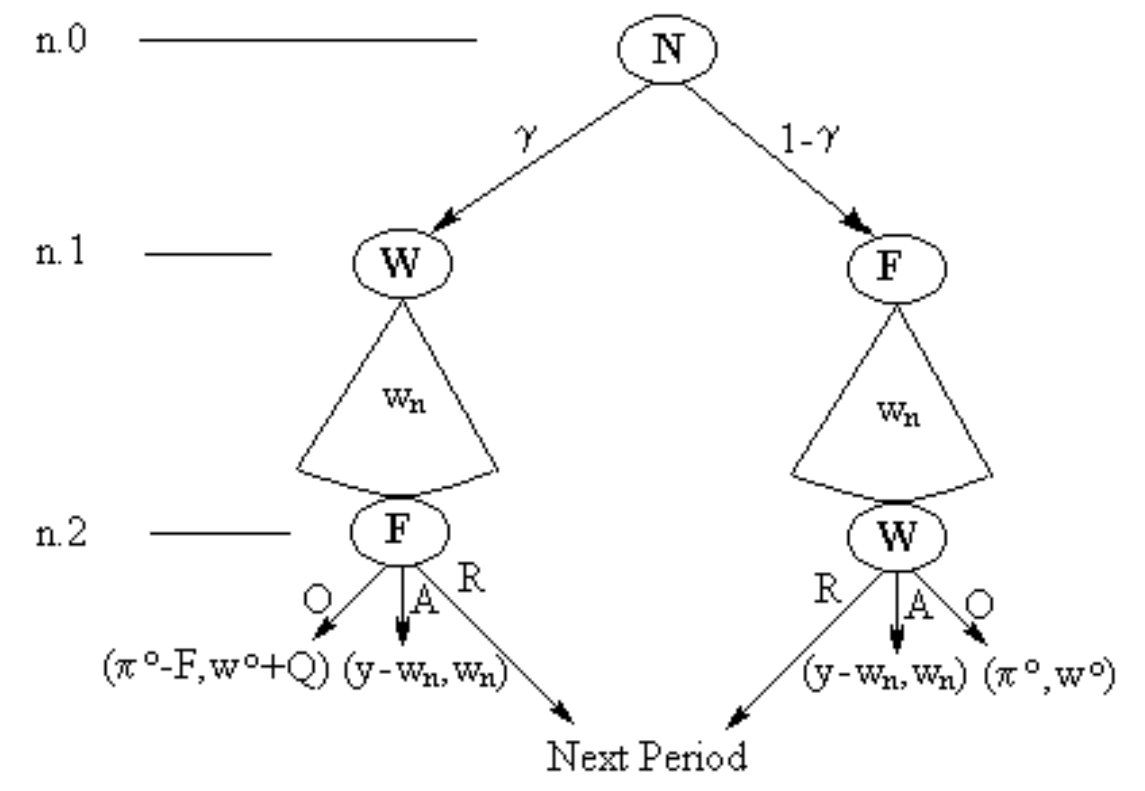

Figure 1: Bargaining game

take her outside option, the firm gets $\pi^{o}$ and the worker earns the outside wage $w^{o}$. If it is the firm which fires the worker, it has to pay the firing cost $F$. In the latter case, the payoffs are respectively $\pi^{o}-F$ for the firm and $w^{o}+Q$ for the worker.

3. If $w_{n}$ is rejected, the game moves onto a new bargaining round. The parties's flow payoffs in this circumstance are normalized to zero.

These moves are illustrated by the choices at stages n.1 and n.2 in figure 1 .

A note is necessary regarding the effect of outside options on the bargaining outcome. The extensive form of the game makes it clear that we allow agents to take their outside option only after receiving an offer. Shaked (1987) has proved that if each party can take its outside option immediately after its offer has been rejected there are multiple equilibria in the infinite horizon game. In labour markets, though, it seems realistic to assume that an employer can make a last offer to match an outside option before a worker abandons the firm. Shaked calls such a market a bazaar. In such a market outside options cannot act as threat points ("take it or leave it" offers are not credible), but just provide a lower bound on the bargaining outcome. 


\section{Equilibrium payoffs and dismissal costs}

\subsection{The irrelevance of dismissal costs}

We have seen that firing costs alter the firm's and worker's decision problem by reducing the firm's outside option. In order to understand how they may affect actions and payoffs it is essential to comprehend what determines the firm's outside option in situations in which wages are determined by bargaining.

Bargaining arises due to the existence of quasi-rents from the relationship. Effectively, if outside options are expressed net of (non-statutory) turnover costs, quasi-rents can only stem from past expenditures. Outside options, instead, depend on both past and future investment. In fact, one could break the total firm's return to the outside activity into two components: the residual value of past investment and the expected present value of future returns from investment in the outside activity net of investment costs. The second component is zero in equilibrium with free entry. It has to be non-negative since trade is voluntary and it cannot be positive as it would imply an infinite demand for the alternative activity $^{7}$. Conversely, there is no reason, in general, for the resale or recycling value of the firm's tangible and intangible assets to be zero unless the initial cost of investment is fully sunk due to complete specificity or irreversibility.

In fact, most of the literature on dismissal costs assumes that search is the only investment activity (if any) firms are engaged in. This is equivalent to assuming full irreversibility, as search costs are a classic example of sunk cost. Allowing for firms' investment in human capital, as in Acemoglu (1997) and similar models, does not make the point any less relevant. Investment in workers' human capital is also fully irreversible from the firm's point of view, as it is embodied in the worker.

This is crucial for the effect of dismissal costs on the equilibrium outcome. In all the models in which the firm's past investment is fully irreversible the firm's outside option is zero.

The effect of the availability of outside options on equilibrium payoffs in bargaining games has been explored in Stähl (1972), Binmore (1985) and Binmore, Rubinstein and

\footnotetext{
${ }^{7}$ Familiriaty with markets and/or customers may imply that in equilibrium some firms, but not all, may enjoy strictly positive ex ante rents from a new business. Yet, these rents must stem from the previous activity and are thus included in the first component.
} 
Wolinsky (1986). In line with this literature, the equilibrium concept we use is that of subgame perfection. Strategies must be a Nash equilibrium in every subgame, thus ruling out incredible threats.

The Outside Option Principle implies that either a party's outside alternative exceeds what she could obtain in the original (without outside options) game or it does not provide her with a credible threat, hence cannot affect the equilibrium outcome. Put differently, an outside option matters only if, in equilibrium, it is binding with strictly positive probability.

If past investment is fully irreversible, firing costs cannot affect equilibrium payoffs, as $\pi^{o}$, the firm's return to the outside activity in the absence of firing restrictions, is zero. In this case, dismissal costs lower the firm's outside option but, since the latter is already not binding in the frictionless equilibrium, they cannot affect equilibrium payoffs. Intuitively, if there are gains from trade, the firm will never fire the worker and take its outside option. The following proposition characterizes the equilibrium.

Proposition 1. If $\pi^{o}$, the firm's outside option in the absence of frictions, is zero and there are gains from trade $\left(y \geq w^{o}\right)$, firing costs have no effect on the equilibrium payoffs. In the unique subgame perfect equilibrium trade takes place immediately and, as the time interval between offers goes to zero $(\Delta \rightarrow 0)$, the equilibrium wage converges to

$$
w^{*}=\max \left\{\gamma y, w^{o}\right\}
$$

Proof. The result is just an application of the Outside Option principle to the random proposer model of Binmore (1987). Binmore proves that, in the absence of outside options, the equilibrium wage converges to $\gamma y$ for $\Delta \rightarrow 0$.

The outside option only acts as a constraint on the above solution ${ }^{8}$ and, provided it can be taken only after rejecting an offer by the counterpart, the perfect equilibrium is unique. Osborne and Rubinstein p. 55-58 provide a detailed proof of this second result in the case of Rubinstein (1982) alternating offer model.

The first term in the curly bracket in equation (1), is the worker's payoff when the outside option in non-binding. The worker's share of the surplus increases with the probability that

\footnotetext{
${ }^{8}$ Strictly speaking the firm would be indifferent between trading and not trading when $y=w^{o}$. We deal with ties by assuming throughout that whenever the parties are indifferent they do trade.
} 
she is selected to make an offer. The second term implies that the worker's payoff cannot fall below the value of its outside option, since otherwise she could do better by quitting. In any case, if there are gains from trade the firm makes nonnegative profits and it has no incentive to fire the worker. Its (negative) outside option $-F$ is never binding.

The logic of the result is clear: a negative outside option cannot affect the equilibrium outcome whenever the continuation payoff is non-negative. Furthermore, dismissal costs cannot affect the equilibrium outcome even in case of separation. In fact, the following result can be proved.

Proposition 2. If $\pi^{o}$, the firm's outside option in the absence of frictions, is zero and trade is not efficient $\left(y<w^{o}\right)$, there exists a unique subgame perfect equilibrium in which the firm never fires the worker. As $\Delta \rightarrow 0$, the worker quits the firm to take her outside option with minimum delay.

\section{Proof. See Appendix A}

Proposition 2 has two implications. First, separation is always efficient ${ }^{9}$, despite the existence of statutory dismissal costs. Secondly, severance of the relationship is costless to the firm, since it takes the form of a quit. The intuition is the following. When separation is efficient, it is not possible for the firm to make nonegative profits and for the worker to obtain a wage no smaller than the alternative wage. The worker cannot impose negative profits on the firm, though, since the firm can secure a minimum payoff of zero by delaying forever. The best the worker can do is to take her outside option as soon as possible.

In brief, firing is an off-equilibrium strategy for the firm. So, when $\pi^{o} \leq 0$, firing costs cannot have any effect on the equilibrium outcome. They do not affect either payoffs or the separation decision in any equilibrium unemployment model in which firms' investment is completely irreversible and wages are determined by efficient bargaining ${ }^{10}$.

\footnotetext{
${ }^{9}$ In general, if the firm employs more than one worker, bargaining over wages only (right to manage) results in inefficient underemployment or, equivalently, excessive separation. The outcome is efficient only if marginal returns to labour are constant. This is what most literature on search unemployment assumes. All our results would still apply to a decreasing returns to labour world under efficient bargaining. This would result if the firm bargained either with the marginal worker over wages only, or with a union with utilitarian preferences and identical members over both wages and employment. See Bertola and Caballero (1994) and McDonald and Solow (1988) for instances of each of the two cases.

${ }^{10}$ The conclusion would survive intact despite capital being employed in production in the rather unrealistic case in which there is a perfect market in capital and no costs of adjustment. In such a perfect world, capital does not affect the firm's opportunity cost of bargaining.
} 
The result that firing costs affect equilibrium payoffs and separation rates in models of voluntary separation with irreversible investment stems from assuming that they alter workers' and firms' threat points. This is equivalent to assuming that the firm can be obliged to play an off-equilibrium strategy.

It has to be noted that in many cases the alternative to reaching an agreement which preserves employment of all the existing labour force is a reduction in the labour force. If layoffs are not associated with any scrapping of assets with positive resale value - i.e. if machines are idled rather than sold - the relevant outside option would be the non-positive return on the unused assets and propositions 1 and 2 would still apply.

The usual argument provided to support a positive effect of dismissal costs on wages when firm's investment is fully specific is that workers can oblige the firm to fire them by reducing effort, if the latter is not observable by third parties. Obviously, a necessary condition must be that trade concerns a flow of goods and services and a contract is in place. This is equivalent to say that workers can renegotiate their contract wage up, as long as this is lower than their payoff in case of firing. By reducing their marginal product below the contract wage, they can increase the firm's cost of bargaining. This argument is subject to two orders of objections. First, if the firm observes effort and lockouts are legal, the firm would respond to a reduction in effort by locking out and could not be forced by workers to fire them ${ }^{11}$. Namely, the workers' threat to inflict a cost onto the firm is not credible, as wages are not paid during a lockout. The bargaining process would still take the form described above and the outcome would still be the one described in propositions 1 and 2. A second and even more fundamental objection to the argument that workers can threat to reduce effort if a contract is in place is that, if this is the case, such a contract is not incentive-compatible and one is left wondering why a rational firm would agree to it in the first place. Some kind of performance-related pay would clearly be preferable from the firm's point of view and under symmetric information it would be unlikely to entail significant transaction $\operatorname{costs}^{12}$.

It is hard to think of ways in which workers can oblige a firm to play a suboptimal strategy

\footnotetext{
${ }^{11}$ The possibility that workers reduce effort and the firm's payoff during bargaining is analysed in Cramton and Tracy (1992) and Moene (1988). Both assume that workers cannot force on the firm a negative payoff, or anyway one which is lower than the payoff during a lockout.

${ }^{12}$ For a certain degree of wage rigidity to be optimal from the firm's point of view when workers control effort levels, it must be the case that the firm observes only a noisy signal of workers' effort. Otherwise, it has no incentive to insure workers against punishment in case of underperformance.
} 
when effort is perfectly observable, though only by the parties involved in the match. This is not to say that the issue of how to discipline workers when dismissal is a costly option for the firm is not relevant. Yet, it does not seem that the right framework to think about this problem is one in which information is symmetric and separation voluntary. As we will see in the section 3.4, though, once we move away from this set up it is not so clear cut that dismissal costs are welfare-reducing.

\subsection{Positive equilibrium effects of dismissal costs}

Dismissal costs do not affect the set of equilibrium strategies in models of voluntary separation if the market value of past investment is not positive. So, for them to have any effect on equilibrium payoffs it has to be the case that either the firm can be forced to play a suboptimal strategy or that its outside option is strictly positive due a positive resale value of its assets.

Let us deal with the latter case first. If the firm's assets are only partly specific, dismissal costs reduce their value outside the relationship if separation is initiated by the firm. Intuitively, in this case they must affect equilibrium payoffs.

Assume for simplicity that the firm's capital (including all tangible and intangible assets) does not depreciate and that the investment cost was paid upfront, so that the flow opportunity cost of capital does not affect the payoffs during bargaining. In terms of our set up, then, $y$ would be the present discounted value of the surplus from the match gross of the opportunity cost of capital per worker installed and the outside option $\pi^{o}$ would be the resale value of the stock of capital per head net of all shut-down expenditures (per head) excluding statutory dismissal costs.

It is clear that in this case firing costs do affect equilibrium payoffs when the firm's outside option is binding ${ }^{13}$, since they reduce the net payoff in case the firm's takes its outside option. Their effect is summarized in the following result.

Proposition 3. Suppose $\pi^{o}$, the firm's outside option in the absence of frictions, is strictly positive and there are gains from trade $\left(y \geq \pi^{o}+w^{o}\right)$. In the unique subgame perfect

\footnotetext{
${ }^{13}$ I am grateful to Paola Manzini for pointing this out to me. Manzini and Snower (1995) analyse this case in a version of Shaked and Sutton (1984) in which the endogenous outside option is positive if outsiders are more profitable than insiders.
} 
equilibrium trade takes place immediately and, as the time interval between offers goes to zero $(\Delta \rightarrow 0)$, the equilibrium wage converges to

$$
w^{*}= \begin{cases}\max \left\{\gamma y, w^{o}\right\} & \text { if } y-\max \left\{\gamma y, w^{o}\right\} \geq \max \left\{\pi^{o}-F, 0\right\} \\ y-\max \left\{\pi^{o}-F, 0\right\} & \text { if }(1-\gamma) y<\max \left\{\pi^{o}-F, 0\right\} .\end{cases}
$$

Proof. This is exactly the same result as in proposition 1 , but now $\pi^{o}$ is strictly positive and provides a lower bound for the payoff to the firm in the frictionless equilibrium. Firing costs reduce the firm's outside option, but the firm can still secure a minimum payoff of zero by perpetual disagreement.

When the firm's assets have a strictly positive resale value, dismissal costs increase wages and reduce ex post profits over some states of nature through two effects. First, they reduce the firm's outside option, hence its payoff when the option is binding. Second, they reduce the probability that the firm's outside option is binding, thus obliging the firm to accept a lower payoff when the surplus from the match $y$ is low relative to its frictionless outside option. Yet, there is a limit to the distributional effect of firing costs. They cannot reduce the firm's payoff below the disagreement payoff. In other words, firing costs in excess of the resale value of capital per head have no marginal effect on the equilibrium shares of the surplus, as the firm can always secure a zero payoff through perpetual disagreement.

Note that as the worker's bargaining power - her probability of making an offer $\gamma$ converges to zero, we obtain the Walrasian solution: the wage in equation (2) converges to the reservation wage $w^{o}$. If workers are wage-takers, dismissal costs do not have any effect on the equilibrium outcome, despite reducing the firm's outside option. So, unless minimum wage constraints result in involuntary unemployment, dismissal costs cannot alter the equilibrium in the secondary labour market, at least in those sectors of it in which workers have no market power such as burger-flipping jobs. The claim that dismissal regulations may reduce job creation in low-paid, service jobs is inconsistent with workers' wage-taking behaviour.

The other instance in which firing costs can affect the equilibrium outcome is when the firm can be forced to play a suboptimal strategy. What section 3.1 has made clear, though, is that it cannot be the worker which forces the firm to act suboptimally under symmetric (even if possibly private) information about workers' effort. This difference between the end of negotiations because one party voluntarily takes its outside alternative and because 
some exogenous event may end the bargaining process at some point has been emphasized in Binmore, Rubinstein and Wolinsky (1986). It is the second possibility which may enlarge the set of credible threats with respect to the case in which separation can only be due to one party's decision to trade outside.

It is evident that a necessary and sufficient condition for firing costs to affect equilibrium payoffs when the firm's past investment is fully irreversible is that the firm fires the worker with a strictly positive probability. This can be easily seen by assuming that, if the firm and the worker do not reach an agreement within the first bargaining round, negotiations end with probability one and the outcome is deemed a firing. In the unique subgame perfect equilibrium agreement is immediate at wage

$$
w=\gamma\left(y-\pi^{o}+F\right)+(1-\gamma)\left(w^{o}+Q\right)
$$

If the parties do not agree ex ante, each can effectively make a take-it-or-leave-it offer if selected to propose in the unique bargaining round.

The wage in equation (3) coincides with the surplus sharing solution of Burda (1992) and Millard and Mortensen (1997). The result of insider-outsider models à la Lindbeck and Snower that workers are able to push firms to the firing barrier and $w=y+F$ is an even more special case when $\gamma=1$. Lazear's (1990) result, that in a competitive labour market $w=w^{o}+Q$, can be obtained if $\gamma=0$. In general, the cost $F$ paid by the firm affects the wage only proportionally to the probability that workers have a chance to make a take-itor-leave-it offer. If $\gamma=0$, the wage is not affected by costs to the firm which do not accrue to workers.

This clearly exposes the implicit assumptions underlying all models that predict a positive effect of firing costs on equilibrium wages under symmetric information and irreversible firm investment. By assuming that dismissal costs alter threat points on a one-to-one basis, they effectively assume that the bargaining process is a one-shot game and that the disagreement outcome is a firing. The effect of dismissal costs on equilibrium payoffs would clearly be lower if the probability that negotiations end in each bargaining round were less than one. In fact, if the latter is the case, the impact of dismissal costs on wages diminishes the more impatient agents are and the lower is the probability that breakdown takes place soon, as it is shown in Appendix B. 
It is important to note that the model with exogenous breakdown is the only one which has the very strong implication that the impact of dismissal costs on wages is unboundedly increasing in their size. So, it cannot be simply treated as a convenient reduced form. Whatever stance one may have on strategic bargaining ${ }^{14}$, the above result points out the importance, for a meaningful theory of firing costs, of explicitly analysing the mechanism which may force firms to fire workers despite it being suboptimal. For example, in the event that negotiations may be exogenously brought to an end by impatient creditors, the probability of break up may be initially negligible and payments in case of firing more heavily discounted. Also, it is unclear whether in this case the firm would pay dismissal costs. If the firm had enough liquidity, it is difficult to understand how creditors could force it into liquidation. Conversely, if creditors could start a bankruptcy procedure, it is doubtful that the firm would pay firing costs.

All the above results on the effects of dismissal costs on equilibrium stem from the Outside Option Principle ${ }^{15}$ rather than on a specific structure for bargaining costs. Also, allowing for agents to take their outside options at any time would just induce multiple equilibria, but would not change the insight that the only effect of firing costs is to increase the specificity of the firm's assets. If these assets are already fully specific, dismissal costs have no effect unless involuntary (from the firm's point of view) firing is possible.

\section{Firing costs and separation}

As we have argued above, if dismissal costs do not affect equilibrium payoffs they have no real effect. Workers would just quit whenever separation is efficient. Even when firing costs do have distributional consequences and reduce ex post profits, they do not have any real effect if they are a pure transfer and markets are perfect. As Lazear (1990) has noted, competition among workers would bid entrance wages down and leave ex ante profits unchanged. On the other hand, it is argued that firing costs should result in lower turnover if the cost born by the firm exceeds the payment to the worker. This prediction bears a clear resemblance to the theory of tax incidence. Suppose firing costs were a tax - a third party payment -

\footnotetext{
${ }^{14}$ Kreps (1990) rightly points out that the non-robustness of the results of strategic bargaining models to small changes in the bargaining protocol should prevent from attaching too much weight to their conclusions.

${ }^{15}$ Binmore, Shaked and Sutton (1989) provide some empirical evidence supporting the relevance of the Outside Option Principle.
} 
on any separation, whoever initiated it. They could be fully translated onto workers only if the wage setting curve were perfectly inelastic. If the wage setting locus displayed a positive elasticity, a tax on firing would affect firm-level employment.

Dismissal costs differ from a tax on separation, though. Firms do not have to behave passively in the face of negative shocks. They can choose the least costly option between firing a worker and inducing a quit through a payment which compensates the worker for any mobility cost she has to bear.

Mobility costs can be exogenous relocation and search costs or may arise endogenously if workers had enjoyed rents in case of continuation. We concentrate on the latter kind of cost as the former is already included in $w^{o}$. If mobility involves no cost, the worker would just voluntarily quit whenever separation is efficient as we have shown in section 3.1. Workers can get no more than their outside option if they do not leave the firm.

Things are different if mobility is (endogenously) costly for workers. Mobility is costly, whenever the continuation wage $w^{\prime}$ lies strictly above $w^{o}$. In this case, the worker would never quit without a compensation payment. Yet, whenever separation is efficient (i.e. $\left.y<w^{o}+\pi^{o}\right)$, the firm would always prefer to compensate the worker and terminate the relationship. When the joint return within the match is lower than the joint return outside, the parties can always do better by separating. This can be easily seen by noticing that, when $y<w^{o}+\pi^{o}$, we have that

$$
y-w^{\prime}<w^{o}+\pi^{o}-w^{\prime}
$$

If $w^{\prime}>w^{o}$, workers would enjoy a rent $R=w^{\prime}-w^{o}$ in case of continuation, and the firm has to pay $R$ to induce a quit. Yet, even allowing for the voluntary severance payment, the firm's return in case of separation - the right hand side of equation (4) - is always strictly higher than the payoff from continuation $y-w^{\prime}$.

It is useful to reflect on the mechanism through which workers' rents may not disappear when the firm would prefer to fire them. One would expect a worker, faced with a credible threat of redundancy, to accept a wage cut as long as her rent from continuation is positive. This should drive the rent $R$ to zero, when the total surplus from the match is nonpositive, and mobility should be costless. For this to be the case, though, both the firm's firing threat and the worker's offer to accept a wage cut have to be credible. 
The worker's offer may not be credible, if real wages are downward rigid. Real wage rigidity may be due to exogenous institutional constraints, such as minimum wage legislation, but it may also arise endogenously. This is the case if wages are set inefficiently by (right-tomanage) collective agreements or if incentive compatibility considerations require workers to enjoy state-independent rents, as in some efficiency wage models. For example, if firms pay efficiency wages in order to prevent shirking as in Shapiro and Stiglitz (1984), workers prefer a wage cut to being made redundant, but their offer is not credible, as it is not incentive compatible. Alternatively, the firm's threat to fire workers when profits are negative may not be credible, if dismissal regulations make firing costly. Either of these two elements is necessary for mobility to be costly for workers when the firm finds it optimal to terminate the employment relationship. Yet, it is only the second element - dismissal costs - which implies that costly workers' mobility may result in costly separation for firms ${ }^{16}$. Under employment-at-will the firm can fire the worker at zero cost whenever continuation is not profitable and does not need to induce a quit.

Dismissal regulations make separation costly for the firm if (and only if) mobility is costly for the worker. Yet, they have no marginal effect on the separation decision unless the statutory firing cost is binding, that is $R>F$ - the cost of inducing a quit (the worker's foregone rent) is higher than the statutory dismissal cost and the firm prefers to bear the latter. In fact, we can state the following result.

Proposition 4. In the presence of dismissal regulations and independently from any assumption about market structure, the cost to the firm of terminating employment is given by $B=\min \{R, F\}$, where $F$ is the statutory firing cost born by the firm and $R=$ $\max \left\{0, w^{\prime}-w^{o}\right\}$ is any rent that workers might enjoy in case of continuation at wage $w^{\prime}$. Whenever $B=R$, the payment is a pure transfer, whether statutory dismissal costs involve third party payments or not, and separation takes the form of a quit.

Proposition 4 makes it clear that firing costs in excess of $R$ have no marginal effect on the cost of separation unless they increase $R$ itself. So, whether firing costs result in lower turnover or not depends on the mechanism that generates workers' rents.

\footnotetext{
${ }^{16}$ Dismissal costs do not have to be exogenously imposed. As argued in Saint-Paul (1995), it is profitable for firms to tie their hands on firing when separation is involuntary, since workers are willing to accept lower wages in exchange for lower expected mobility costs.
} 
If rents are not the result of dismissal costs, but stem from endogenously determined downward rigid real wages, as it is the case in models of involuntary separation, firing costs result in lower turnover ${ }^{17}$. Firing costs in excess of workers' mobility costs, though, have no marginal effect on the separation rate which is the same as in the case of a pure severance payment equal to $R$. The intuition is the following. In models of involuntary separation utility is non-transferable and, in the absence of firing restrictions, severance takes place whenever the firm's return is negative, even if the joint return within the match is higher than the joint return from separation. Job destruction is inefficiently high, as firms do not internalize the externality, in the form of foregone rent, that severance imposes on workers. Dismissal costs, by making firing costly, induce the firm to continue the match despite a negative return, as long as the loss from continuation is smaller than the cost of dismissal. Provided they do not increase workers' continuation rents ${ }^{18}$ by more than they decrease firms' returns, firing costs efficiently reduce the joint rent from the match at the moment of separation. Firing costs no smaller than workers' continuation rents ensure efficient separation and have no marginal effect on job destruction, as there exists a side payment that both the firm is willing to pay and workers to accept in order to separate efficiently.

Intuitively, whenever utility is non-transferable Coase theorem does not apply and efficiency depends on the initial distribution of property rights on the job. In the absence of dismissal costs, severance takes place whenever the firm's payoff is non-positive whether or not the joint return within the match is strictly lower than the joint return from separation. Dismissal costs reduce the firm's return from separation, by setting a minimum price for the exercise of the right to fire. So, provided they are high enough to ensure that the minimum trade price of the property right equals the value of employment continuation to workers, they induce the firm to terminate the relationship efficiently, when the joint rent from the match is zero. Since private trading of the property right is both possible and desirable when the statutory trade price is set too high, the latter ceases to have any effect and the

\footnotetext{
${ }^{17}$ By involuntary separation, we mean that redundant workers would strictly prefer to be retained as in the dynamic versions of Shapiro and Stiglitz's model analysed in Saint-Paul (1997) and Fella (1998) or the union model under right-to-manage bargaining in Booth (1997).

${ }^{18}$ Dismissal costs may affect workers' rents in models of involuntary separation. For example, this is the case in shirking models of efficiency wage, if courts are unable to distinguish between dismissals for economic and disciplinary reasons, or in right-to-manage collective bargaining models.
} 
efficiency results, as predicted by Coase theorem ${ }^{19}$.

Rents may, instead, be the result of dismissal costs. This is the case in the class of models analysed in section 3.2.

In the case in which dismissal costs increase asset specificity, the continuation wage is given by equation (2) and workers' mobility cost is

$$
R= \begin{cases}\max \left\{\gamma y-w^{o}, 0\right\} & \text { if } y-\max \left\{\gamma y, w^{o}\right\} \geq \max \left\{\pi^{o}-F, 0\right\} \\ y-\max \left\{\pi^{o}-F, 0\right\}-w^{o} & \text { if }(1-\gamma) y<\max \left\{\pi^{o}-F, 0\right\}\end{cases}
$$

In the exogenous breakdown case, the relevant wage is given by (3) and workers' continuation rent is

$$
R=Q+\gamma\left(y-\pi^{o}-w^{o}+F-Q\right)
$$

Dismissal regulations result in higher wages, but do not necessarily result in workers' rents in case of continuation when separation is efficient. In fact, it is evident that the above rents are decreasing in $y$ - the surplus from continuation - and may well be zero for a negative enough shock.

In these models, though, even if firing costs are high enough to result in costly severance, they can never push the cost of separation above the statutory cost $F$. So the latter is not binding and does not affect the separation rate, which is always efficient. In fact, the following result can be proved.

Proposition 5. Legislated dismissal costs do not necessarily result in costly separation for firms. When they do result in costly separation, the cost is increasing in the productivity of the match, but always strictly lower than the statutory dismissal cost F. Hence, firms never fire, but rather induce workers to quit by compensating them for the mobility cost.

Proof. Workers' rent from continuation is an increasing function of $y$. So we can write it as $R(y)$. So whenever separation is efficient - i.e. $y<\pi^{o}+w^{o}$ - workers' mobility cost is strictly smaller than $R\left(\pi^{o}+w^{o}\right)$. In the exogenous breakdown case, evaluation of equation (6) at $y=\pi^{o}+w^{o}$, results in

$$
R\left(\pi^{o}+w^{o}\right)=(1-\gamma) Q+\gamma F
$$

\footnotetext{
${ }^{19}$ We are obviously assuming away any eventual external effect on third parties.
} 
which is at most $F$, as $Q \leq F$.

In the case in which firms' investment has a positive resale value, evaluating the expression in equation (5) at $y=\pi^{o}+w^{o}$, we obtain

$$
R\left(\pi^{o}+w^{o}\right)= \begin{cases}F & \text { if } 0<(1-\gamma)\left(\pi^{o}+w^{o}\right) \leq \pi^{o}-F \\ \gamma \pi^{o}-(1-\gamma) w^{o} & \text { if }(1-\gamma)\left(\pi^{o}+w^{o}\right)>\max \left\{\pi^{o}-F, 0\right\} \\ 0 & \text { otherwise. }\end{cases}
$$

$R\left(\pi^{o}+w^{o}\right)=F$ only if the firm's outside option $\pi^{o}-F$ is positive and binding. Otherwise, $R\left(\pi^{o}+w^{o}\right)$ is strictly smaller than $F$, as can be checked by evaluating the second line of (8). So, the supremum (but not maximum) of the set of minimum payoffs necessary to induce a quit is $F$.

The main result of this section is clear. Firing costs, whether fully received by workers or not, are at worst welfare neutral and at best welfare enhancing, as far as the separation decision is concerned. In models in which separation is efficient they do not alter the separation rate. Conversely, if separation is involuntary, dismissal costs improve welfare by reducing job destruction from an inefficiently high level.

Furthermore, the reduction in separation rates increases firms' marginal returns from investment $^{20}$. Coeteris paribus, this enhances incentives to invest in human (and possibly physical) capital and increases the rate of growth. This further boosts welfare, as investment is too low in the decentralized equilibrium due to the inefficiently high separation rate.

While the above analysis has concentrated on the effect of dismissal costs on ex post payoffs and job destruction, they can obviously affect ex ante payoffs, hence job creation. As emphasized by Lazear (1990), if markets are perfect the effect of firing restrictions on expected profits is fully undone by lower entrance wages and job creation is unaffected. So aggregate employment is unchanged or increased respectively in models of voluntary or involuntary separation. If entrance wages cannot fall by the necessary amount, though, dismissal costs depress job creation. Aggregate employment and welfare unambiguously fall if separation is voluntary.

The aggregate employment and welfare consequences of dismissal costs in the presence

\footnotetext{
${ }^{20}$ Whether dismissal costs also increase workers' marginal returns to human capital investment depends on the mechanism which determines wages. In the simplest efficiency wage models wages are independent not only (and obviously) from individual productivity, but also from the productivity of the average worker.
} 


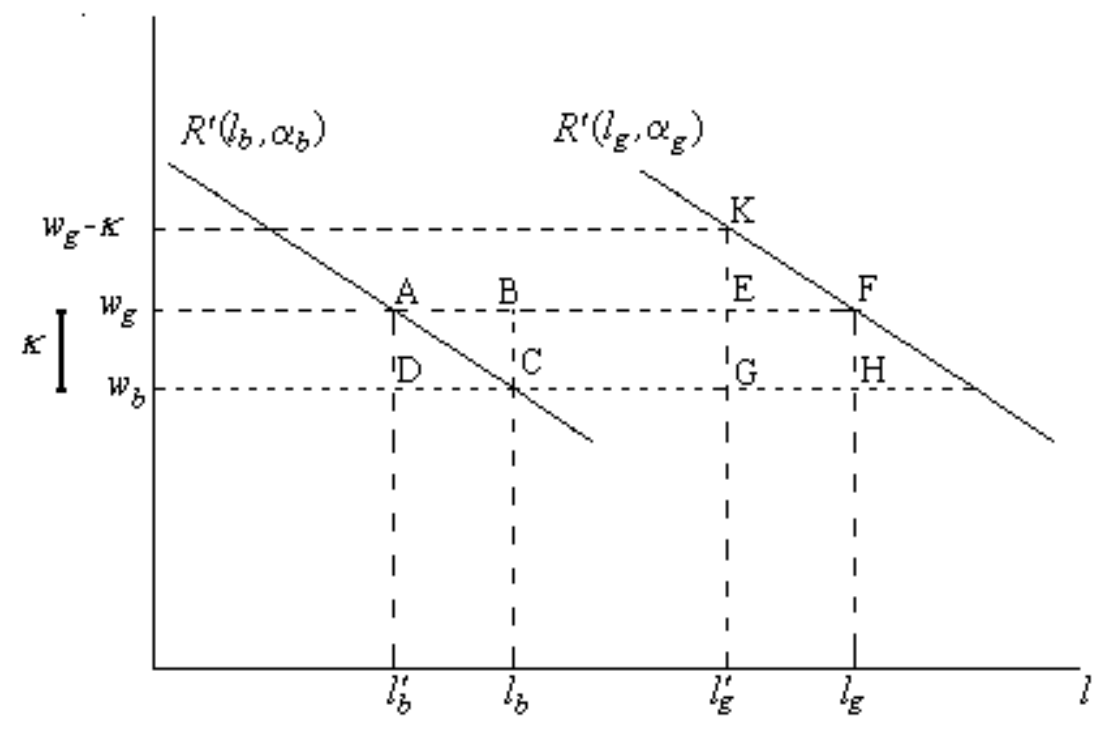

Figure 2: Welfare effects of severance payments in the presence of real wage rigidity

of wage rigidities are less straightforward and partly model-dependent. Yet, it is possible to get some general insight with the use of a simple diagram.

Suppose, that firms in the economy cycle between a high and a low productivity state, represented by the two, constant-slope, labour demand curves in figure 2. The model is a simplified version of the stochastic, competitive model à la Lucas and Prescott (1974) analysed in Bertola and Ichino (1995b). The only difference is that we assume no discounting and that transitions between states are deterministic. There are 0.5 firms in each state and in every period all of them undergo a state reversal with probability one. Mobility entails an exogenous, positive relocation or search cost $\kappa$ for workers. As in Lucas and Prescott (1974), in the frictionless competitive equilibrium high productivity firms have to pay a positive wage premium $w_{g}-w_{b}$ which exactly compensates workers for the mobility cost and mobility is costless. In our simple setup the wage differential equals the mobility cost $\kappa$ and employment at firms in the good and the bad state equals $l_{g}$ and $l_{b}$ respectively. For simplicity we assume that this coincides with full employment of the labour force.

Assume now, that a minimum wage constraint or "equal-pay-for-equal-pay" policy or some other form of real wage rigidity implies that the unique, economy-wide wage is $w_{g}$. Wage compression results in costly worker mobility and involuntary separation. In the 
absence of dismissal costs, the level of employment at contracting firms is too low at $l_{b}^{\prime}$ and there is too much wasteful relocation (and involuntary unemployment), as firing firms do not internalize workers' mobility costs.

The introduction of a severance payment equal to $\kappa$ would be welfare improving in such a set $u^{21}$. The severance payment would increase employment at firing firms and, if entrance wages cannot fall, decrease it at hiring ones. Aggregate employment would be unchanged as the increase in employment $l_{b}-l_{b}^{\prime}$ at contracting firms would be offset by the fall in employment $l_{g}-l_{g}^{\prime}$ at expanding ones ${ }^{22}$. Yet, the fall in turnover would be welfare improving as, due to wage rigidity, the frictionless equilibrium features too much mobility. Since aggregate employment is unchanged, the change in aggregate welfare with respect to the frictionless equilibrium with wage rigidity is given by the change in aggregate production minus the change in total relocation costs. Given that the number of firms in each state 0.5, the change in total product equals one-half the difference between the trapezoids $K F l_{g} l_{g}^{\prime}$ and $A C l_{b} l_{b}^{\prime}$. Since the two labour demand curves have the same slope the net loss is represented by the area $E F H G$. Yet, total mobility costs fall by one-half of the sum of areas $E F H G$ and $A B C D$, as turnover fall from $l_{g}-l_{b}^{\prime}$ to $l_{g}^{\prime}-l_{b}$. This leaves the economy with a net gain equal to one-half the area $A B C D$. Note that if wages at expanding firms were free to fall by the size of the future payment, employment at firing firms would be unaffected and aggregate welfare would be the same as in the first best equilibrium.

If the firing cost were a pure third-party payment, it would have the same effect on employment and turnover, but would be very likely to increase total mobility costs and reduce aggregate welfare. This is the case if it increases the total unit mobility cost - the sum of the firing cost and workers' mobility cost - at a higher rate than it reduces turnover. Only if the firing cost were higher than $\kappa$, would it have the same effect as the severance payment, as firms could induce workers to quit by offering them a voluntary severance payment equal to $\kappa$.

The important result is that what determines whether firing costs affect separation is

\footnotetext{
${ }^{21}$ Obviously, the first best intervention would be the removal of the source of wage rigidity. As we have argued above, though, the constraint on wage flexibility may well be endogenous (e.g. if firms have to pay efficiency wages).

${ }^{22}$ Bertola (1990) demonstrates that allowing for discounting and more general functional forms for labour demand does not alter the general intuition that dismissal costs have little effect on aggregate unemployment in partial equilibrium.
} 
not whether the cost is wasteful or not, but whether wages are rigid. Unless one is sure, that a wasteful firing cost is going to be undone by private negotiation ${ }^{23}$, a pure severance payment is to be preferred. It involves no waste of resources and reduces the opposition of redundant workers' to redeployment as it makes mobility less costly.

\section{Empirical evidence}

Given the distinct implications of models of voluntary and involuntary separation about the desirability of dismissal costs one would like to ascertain their relative empirical relevance.

Indirect evidence supporting the view that inefficient separation is a relevant feature of real-world labour markets comes from studies such as Krueger and Summers (1988) which demonstrate the existence of non-competitive industry-specific rents. Case and survey studies by Raff and Summers (1987), Kaufman (1987) and Blinder and Choi (1992) find support to the causes of real wage rigidity emphasized by the efficiency wage literature.

As we have seen above, one testable prediction of models of involuntary separation is a negative correlation between the probability that the marginal job is destroyed and firing costs. A recent study by Nickell (1998) finds a strong positive correlation in a cross-country regression between an index of job security and employees' tenure. While one has to be careful in interpreting this result which is based on a limited number of observations and an index which, by its own nature, has a certain degree of ad-hocness, it seems difficult to reconcile with the predictions of models of voluntary separation.

A second testable implications which distinguishes the two classes of models is the response of job creation and destruction to a reduction in dismissal regulations. If separation is voluntary, a labour market reform that reduces firing costs should result in higher job destruction only if it boosts job creation. Since separation is efficient anyway, a reduction in dismissal costs can increase job destruction only if it increases hiring and workers' reservation wages. Enhanced job creation should lead (rather than lag) higher rates of job destruction. Conversely, if separation is involuntary, weakening of job security legislation should result in higher job destruction at firms for which dismissal costs are binding. Job creation would increase on impact only if market imperfections imply a negative relationship between job

\footnotetext{
${ }^{23}$ This is the case only in the absence of significant informational asymmetries and other forms of transaction costs.
} 
creation and dismissal costs and the policy change is credible. Again, the empirical evidence seems more supportive of this second scenario. Bertola and Ichino (1995b) provide evidence that the partial deregulation of the Swedish and Italian labour markets of the early Nineties was characterized by very high rates of job destruction by historical standards and very little job creation.

Of course, firms dislike dismissal costs, at least ex post. Even if they were welfare improving, firing restrictions alter the cost of separation for firms and, ex post, they would always prefer not to have to pay them and would press for "increased flexibility" in downturns.

Clearly, dismissal costs are not necessarily a panacea even if separation is involuntary. First, if entry wages cannot fall by the full amount necessary to compensate for the negative impact of firing costs on firms' profitability, dismissal regulations reduce firms' value and investment. This is the case if, either firing costs are binding and involve third party payments, so that workers are not willing to reduce wages by the full amount of the firm's cost ${ }^{24}$ or if some form of market imperfection prevents entrance wages from falling to leave ex ante profits unchanged. In this case, dismissal regulations may reduce job creation. Second, if firing costs increase workers' rents and wages, their impact on the separation rate is reduced. The net welfare effect would then be ambiguous, as one would expect in a second best world.

\section{Conclusion}

This paper uses a strategic bargaining model to reassess the effect of firing costs in models of voluntary separation.

It shows that firing, as opposed to inducing workers to quit, is always an off-equilibrium strategy in this class of models. Dismissal costs can affect payoffs in only two cases: if some exogenous event may force the firm to fire the worker despite it being suboptimal, or if the firm's assets are only partly specific to the relationship. In this latter case, dismissal costs by increasing the specificity of the firm's assets, reduce the probability that its outside option is binding and ex post expected profits.

Most importantly, we show that, in any case, dismissal restrictions do not alter the separation rate in models in which separation is voluntary in the frictionless equilibrium,

\footnotetext{
${ }^{24}$ See again Fella (1998).
} 
as firms always find it profitable to induce workers to quit whenever separation is efficient. Involuntary separation is an essential feature of a world in which firing costs result in a lower probability of separation. In such a world, they may be welfare improving, as the separation rate is inefficiently high in the absence of firing restrictions.

The empirical evidence on the effect of job security on tenure is broadly consistent with the involuntariness of separation. 


\section{References}

Acemoglu, Daron (1997), 'Training and Innovation in an Imperfect Labour Market', Review of Economic Studies 64, 445-464.

Azariadis, Costas (1975), 'Implicit Contracts and Underemployment Equilibria', Journal of Political Economy 83, 1183-1202.

Bertola, Giuseppe and Caballero, Ricardo (1994), 'Cross-Sectional Efficiency and Labor Hoarding in a Matching Model of Unemployment', Review of Economic Studies 61, 435-456.

Bertola, Giuseppe and Ichino, Andrea (1995a), 'Crossing the River: A Comparative Perspective on Italian Employment Dynamics', Economic Policy: A European Forum 21, 359-415.

Bertola, Giuseppe and Ichino, Andrea (1995b), 'Wage Inequality and Unemployment: U.S. versus Europe', NBER Macroeconomics Annual pp. 359-415.

Binmore, Ken G. (1985), Bargaining and Coalitions, in Alvin E. Roth, ed., 'Game-Theoretic Models of Bargaining', Cambridge University Press, Cambridge: UK, pp. 269-304.

Binmore, Ken G. (1987), Perfect Equilibria in Bargaining Models, in Ken G. Binmore and Partha Dasgupta, eds, 'The Economics of Bargaining', Blackwell, Oxford: UK, pp. $77-105$.

Binmore Ken G., Ariel Rubinstein and Wolinsky, Asher (1986), 'The Nash Bargaining Solution in Economic Modelling', Rand Journal of Economics 17, 176-188.

Binmore Ken G., Ariel Shaked and Sutton, John (1989), 'An Outside Option Experiment', Quarterly Journal of Economics 104, 753-770.

Booth, Alison L. (1997), An Analysis of Firing Costs and Their Implications for Unemployment Policy, in Dennis Snower and Guillermo de la Dehesa, eds, 'Unemployment Policy: How Should Governments Respond to Unemployment', Cambridge University Press, Cambridge: UK, pp. 359-388.

Burda, Michael C. (1992), 'A Note on Firing Costs and Severance Benefits in Equilibrium Unemployment', Scandinavian Journal of Economics 94, 479-489.

Cabrales, Antonio and Hopenhayn, Hugo A. (1995), Job Dynamics, Correlated Shocks and Wage Profiles, mimeo Universitat Pompeu-Fabra.

Cramton, Peter C. and Tracy, Joseph S. (1992), 'Strikes and Hold Outs in Wage Bargaining: Theory and Data', American Economic Review 82, 100-121.

Fella, Giulio (1998), Efficiency Wage and Efficient Redundancy Pay, mimeo LSE, European Economic Review, forthcoming.

Hart, Oliver D. (1983), 'Optimal Labour Contracts under Asymmetric Information: An Introduction', Review of Economic Studies 50, 3-35. 
Hopenhayn, Hugo and Rogerson, Richard (1993), 'Job Turnover and Policy Evaluation: A General Equilibrium Analysis', Journal of Political Economy 101, 915-938.

Jansen, Marion (1997), Tenure, Training and Unemployment: May Firing Costs Increase Productivity, mimeo Universitat Pompeu Fabra.

Kreps, David M. (1990), Game Theory and Economic Modelling, Oxford University Press, Oxford.

Lazear, Edward P. (1990), 'Job Security Provisions and Employment', Quarterly Journal of Economics 105, 699-726.

MacLeod, W. Bentley and Malcomson, James M. (1993a), 'Investments, Holdup and the Form of Market Contracts', American Economic Review 83, 811-837.

MacLeod, W. Bentley and Malcomson, James M. (1993b), 'Specific Investment and Wage Profiles in Labour Markets', European Economic Review 37, 343-354.

MacLeod, W. Bentley and Malcomson, James M. (1995), 'Contract Bargaining with Symmetric information', Canadian Journal of Economics 28, 336-367.

Manzini, Paola and Snower, Dennis J. (1996), On the Foundations of Wage Bargaining, CEPR discussion paper n. 1514.

McDonald, Ian M. and Solow, Robert M. (1981), 'Wage Bargaining and Employment', American Economic Review 71, 896-908.

Millard, Stephen P. and Mortensen, Dale T. (1997), The Unemployment and Welfare Effects of Labour Market Policy: A Comparison of the US and the UK, in Dennis Snower and Guillermo de la Dehesa, eds, 'Unemployment Policy: How Should Governments Respond to Unemployment', Cambridge University Press, Cambridge: UK, pp. 545571.

Moene, Karl O. (1988), 'Unions' Threats and Wage Determination', Economic Journal 98, 471-483.

Mortensen, Dale T. and Pissarides, Christopher A. (1994), 'Job Creation and Job Destruction in the Theory of Unemployment', Review of Economic Studies 61, 397-415.

Nickell, Stephen J. (1998), Job Tenure and Labour Reallocation: a Partial Overview, Paper presented at the conference on Job Tenure and Labour Reallocation, 24-25 April 1998, CEP, London School of Economics.

Nickell, Stephen J. and Layard, Richard (1997), Labour Market Institutions and Economic Performance, in Oliver Ashenfelter and David Card, eds, 'Handbook of Labour Economics, Vols. 3, 4', North Holland, Amsterdam. Forthcoming.

Osborne, Martin J. and Rubinstein, Ariel (1982), Bargaining and Markets, Academic Press, San Diego: California.

Rubinstein, Ariel (1982), 'Perfect Equilibrium in a Bargaining Model', Econometrica 50, 97109. 
Saint-Paul, Gilles (1997), Dual Labor Markets: A Macroeconomic Perspective, MIT Press, Cambridge: Massachussets.

Shaked, Avner (1987), Opting out: Bazaars versus High Tech Markets, STICERD Theoretical Economics Discussion Paper 159, London School of Economics.

Shapiro, Carl and Stiglitz, Joseph E. (1984), 'Equilibrium Unemployment as a Worker Discipline Device', American Economic Review 74, 433-444.

Stiglitz, Joseph (1997), Theories of Wage Rigidity, in J. L. Butkiewicz et al., ed., 'Keynes' Economic Legacy: Contemporary Economic Theories', Praeger, New York, pp. 153206. 


\section{Appendix A: Proof of proposition 2}

Proof of proposition 2. From the result in proposition 1, when $y<w^{o}$, the firm cannot make positive profits and grant the worker a wage no smaller that her outside option. If the parties cannot agree ex ante, at node n.1 the firm will propose a wage no greater than $y$ and the worker will take her outside option. On the other hand, when responding to a proposal, the firm will reject with probability one any offer which results in negative profits, because, she can secure a payoff equal to zero by perpetual disagreement. For the same reason, the firm will never fire and pay the dismissal cost. So the supremum of the worker's ex ante expected payoffs at node $n .0$ is

$$
w=(1-\pi) w^{o}+\pi \max \left\{y, \delta^{\Delta} w\right\}
$$

The worker can obtain at most $w^{o}$ if the firm is selected to make an offer in the following bargaining round and the higher between $y$, the highest payoff she can obtain by inducing the firm to trade (the firm making zero profit), and the highest payoff she can obtain by making an unacceptable offer in order to take her outside option if the firm is chosen to propose in the next bargaining round. In both cases, it is easy to check that immediate agreement is not possible as the firm's payoff $y-w$ is strictly negative when $y<w^{o}$ and the firm would not accept. So, the parties will start bargaining and we know their optimal behaviour along the right part of the game tree in figure 1; viz. when the firm is selected to propose.

Let us now consider what happens when the worker is selected to make an offer. The supremum of the worker's ex ante expected payoffs takes two values. It is

$$
w=(1-\pi) w^{o}+\pi y
$$

if the surplus from trade $y$ is not to low, that is if $y \geq \delta^{\Delta} w$. In this case, the worker is better off making an offer at node n.1 that the firm will accept and obtaining $y$ rather than waiting to take her outside option in a future round. If, otherwise, $y<\delta^{\Delta} w$ the supremum of the worker's payoffs is

$$
w=\frac{(1-\pi) w^{o}}{1-\pi \delta^{\Delta}}
$$


and the worker prefers delaying and waiting to take her outside option. The value of $y$ which partitions the set of optimal actions is $y^{*}=\delta^{\Delta} w$ where $w$ is given by equation (11).

If $y<y^{*}$ it is optimal for the worker never to trade and wait for a chance to take her outside option. For $\Delta \rightarrow 0, y^{*}$ converges to $w^{o}$. As the time interval between bargaining rounds tends to zero, the worker never finds it optimal to trade and takes its outside option with negligible delay .

The equilibrium can be supported by the following strategy:

1. At stage n.1 the firm offers a wage $w=y$ whenever chosen to make an offer and the worker offers a wage $w=w^{o}$ when chosen.

2. At stage n.2 the firm rejects any offer of $w>y$ while the worker takes her outside option when offered anything less than $w^{o}$.

Given 1, 2 is always a best response if $y<w^{o}$. 


\section{Appendix B: Equilibrium payoffs in the exogenous breakdown case}

To derive the effect of dismissal costs on equilibrium payoffs in the case in which the firm can be forced by some exogenous event to (suboptimally) fire the worker we adapt the exogenous breakdown model outlined in Sutton (1986). The structure of the bargaining game is represented in figure 3. In each bargaining round of length $\Delta$, there is a probability $1-e^{-\lambda \Delta}$ that the game is exogenously ended and the outcome is deemed a firing. This is represented by Nature's choice at node n.-1. The payoffs are $w^{o}+Q$ for the worker and $\pi^{o}-F$ for the firm. In what follows we assume the firm's gross return to the outside activity $\pi^{o}=0$, but the assumption can be easily relaxed. With the complementary probability $e^{-\lambda \Delta}$

the game continues with an offer by one of the parties to the other as in the main text. If the parties fail to reach an agreement in the current round of negotiations, the game moves to a new bargaining round identical to the previous one.

Let $w_{\lambda}$ be the infimum (supremum) of ex ante subgame perfect equilibrium payoffs to the worker in the modified game. It is

$$
w_{\lambda}=\left(1-e^{-\lambda \Delta}\right)\left(w^{o}+Q\right)+e^{-\lambda \Delta}\left[(1-\gamma) \max \left\{w^{o}, \delta^{\Delta} w_{\lambda}\right\}+\gamma\left(y-\delta^{\Delta} \max \left\{\Pi_{\lambda}, \Pi^{d}\right\}\right)\right]
$$

were $\Pi_{\lambda}$ is the lowest(highest) ex ante payoff to the firm defined by

$$
\Pi_{\lambda}=-\left(1-e^{-\lambda \Delta}\right) F+e^{-\lambda \Delta}\left[(1-\gamma)\left(y-\max \left\{w^{o}, \delta^{\Delta} w_{\lambda}\right\}\right)+\gamma \delta^{\Delta} \max \left\{\Pi_{\lambda}, \Pi^{d}\right\}\right]
$$

and

$$
\Pi^{d}=-\frac{1-e^{-\lambda \Delta}}{1-e^{-(\lambda+r) \Delta}} F
$$

is the firm's expected payoff in case of perpetual disagreement. With probability $1-e^{-\lambda \Delta}$, the firm faces an expected cost equal to the expected present value of the firing cost $F$. Symmetrically, the worker's expected payoff in case of perpetual disagreement is

$$
W^{d}=\frac{1-e^{-\lambda \Delta}}{1-e^{-(\lambda+r) \Delta}}\left(w^{o}+Q\right)
$$

It is easy to check that if the worker's outside option $w^{o}$ and the firm's disagreement payoff are non-binding, the infimum and supremum of the worker's payoffs coincide and take 


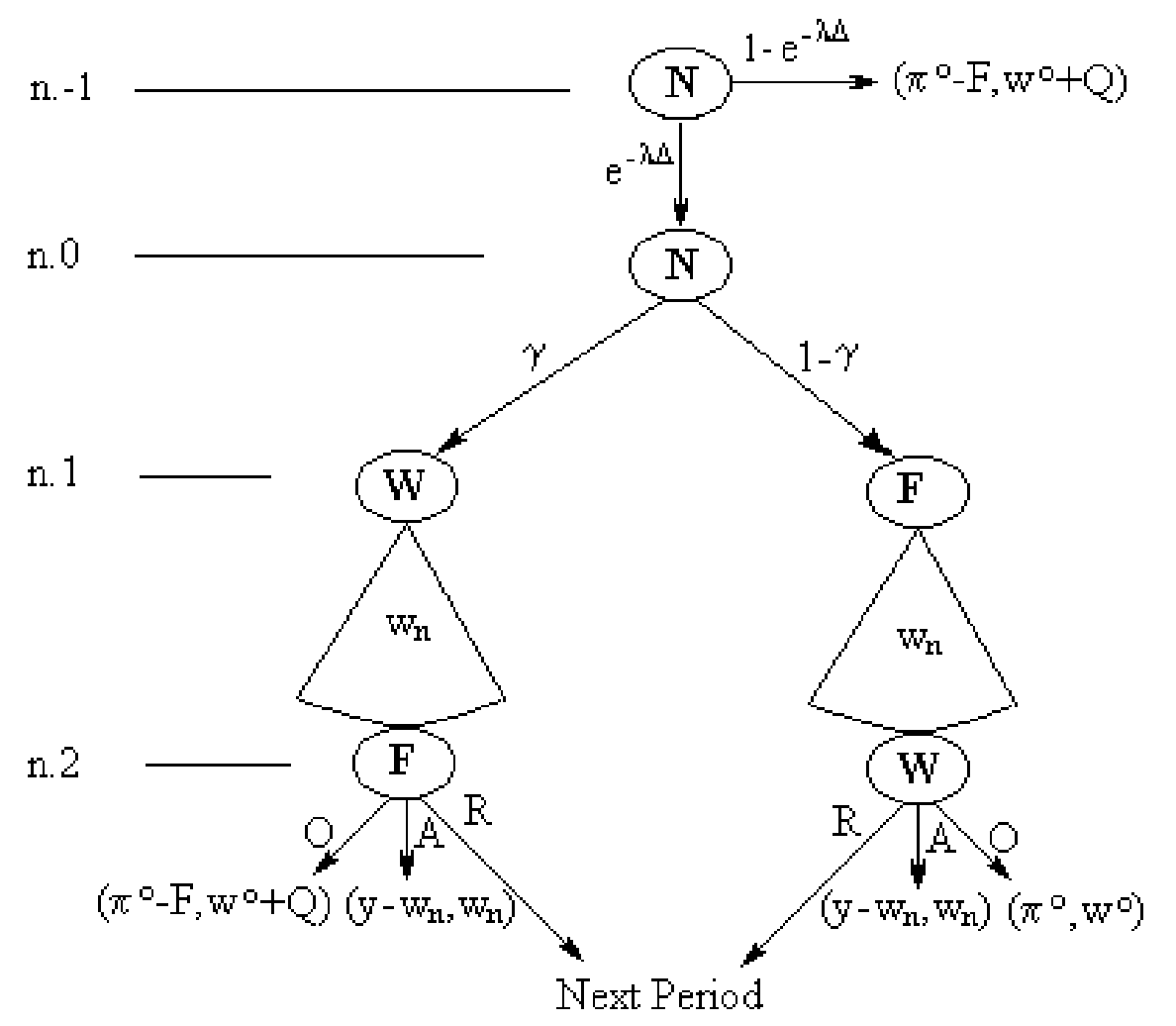

Figure 3: Bargaining game with exogenous breakdown

the common value

$$
w_{\lambda}=e^{-\lambda \Delta} \gamma y+\frac{1-e^{-\lambda \Delta}}{1-e^{-(\lambda+r) \Delta}}\left[(1-\gamma)\left(w^{o}+Q\right)+\gamma F\right]
$$

which for $\Delta \rightarrow 0$ converges to

$$
w_{\lambda}=\gamma y+\frac{\lambda}{\lambda+r}\left[(1-\gamma)\left(w^{o}+Q\right)+\gamma F\right]
$$

$w_{\lambda}$ can also be recovered as the Nash bargaining solution to

$$
\max _{w}\left(w-w^{d}\right)^{\gamma}\left(y-\pi^{d}\right)^{1-\gamma}
$$

where $\pi^{d}$ and $w^{d}$ are the limits for $\Delta \rightarrow 0$ of the disagreement payoffs $\Pi^{d}$ and $W^{d}$ in equations 
(14) and (15).

The firm's outside option $-F$ is never binding if continuation is efficient, since it is strictly smaller than the disagreement payoff $\pi^{d}$ if $y>w^{o}$. The worker's outside option instead still acts as a constraint on the worker's payoff.

As argued in the main text, the worker's payoff is decreasing in the discount rate and increasing in the instantaneous probability of breakdown $\lambda$. The equilibrium payoff converges from below to the one in the single round bargaining game with exogenous breakdown analysed in the main text for $\lambda$ diverging to infinity or $r$ converging to zero. In the first case, the probability of immediate breakdown converges to one. In the second one, the timing of the breakdown is irrelevant as the parties are infinitely patient.

The equilibrium can be supported by the following strategy:

1. At stage $n .1$ both the worker and the firm offer $w=w_{\lambda}$ if selected to make an offer.

2. At stage n.2 the worker (the firm) accepts any offer of $w \geq w_{\lambda}\left(w \leq w_{\lambda}\right)$ and rejects anything less (more) that $w_{\lambda}$.

Given 1, 2 is a best response and viceversa and immediate agreement is optimal. 